\title{
Milliliter per Dose
}

National Cancer Institute

\section{Source}

National Cancer Institute. Milliliter per Dose. NCI Thesaurus. Code C124459.

A unit of measure expressed in milliliter(s) per dose. 